\title{
Microforceps-Assisted Diagnosis of Cystic Pancreatic Neuroendocrine Tumor
}

\author{
Guru Trikudanathan ${ }^{1}$, Dale Snover ${ }^{2}$ and Shawn J Mallery ${ }^{1}$ \\ ${ }^{1}$ Division of Gastroenterology, ${ }^{2}$ Department of Pathology, University of Minnesota, Minneapolis, MN, USA
}

A 72-year-old white woman with a history of hyperparathyroidism with previous parathyroidectomy was persistent vomiting. Contrast-enhanced computed tomography revealed a $2.9-\mathrm{cm}$ complex cystic mass with a thickened irregular enhancing wall in the pancreatic tail (Fig. 1A). Endoscopic ultrasonography (EUS) revealed a 29-mm anechoic lesion with asymmetric wall thickening (Fig. 1B). EUS-guided fine-needle aspiration (EUS-FNA) with a 19-G needle (Expect Needle; Boston Scientific, Natick, MA, USA) showed a cyst fluid carcinoembryonic antigen (CEA) level of $1.6 \mathrm{ng} / \mathrm{mL}$ and amylase level of $67 \mathrm{U} / \mathrm{L}$, and cytological analysis revealed scant cellularity negative for malignancy. Under direct EUS visualization, the Moray microforceps (US Endoscopy, Mentor, OH, USA) was advanced through the 19-G needle and biopsy of the cyst wall was performed (Fig. 1C). Biopsy revealed a pancreatic epithelium with strongly positive staining for chromogranin and synaptophysin, consistent with pancreatic neuroendocrine tumor (PNET; Fig. 2), with 3\%-20\% of tumor cells positive for Ki-67. She was referred for distal pancreatectomy.

Though typically solid, PNETs may present as cystic lesions and account for $<10 \%$ of all pancreatic cystic neoplasms (PCNs). ${ }^{1}$ They usually appear as isolated, non-functional tumors in the body or tail of the pancreas, often associated with

Received: October 1, 2018 Revised: January 2, 2019

Accepted: January 8, 2019

Correspondence: Guru Trikudanathan

Division of Gastroenterology, University of Minnesota, 406 Harvard St SE MMC36, Minneapolis, MN 55455, USA

Tel: +1-860-380-0048, Fax: +1-612-625-5620, E-mail: triku001@umn.edu ORCID: https://orcid.org/0000-0003-3661-4496

cc This is an Open Access article distributed under the terms of the Creative Commons Attribution Non-Commercial License (http://creativecommons.org/ licenses/by-nc/3.0) which permits unrestricted non-commercial use, distribution, and reproduction in any medium, provided the original work is properly cited.
MEN-1 as suspected in our case. ${ }^{2,3}$ Given the risk of malignant potential, management involves surgical resection. Accurate preoperative diagnosis is seldom made with cross-sectional imaging alone, warranting the need for EUS-FNA. The EUS morphology of PNET includes a unilocular cyst, septated cysts, cysts with a microcystic appearance, or mixed solid-cystic masses, and are unlikely to reliably distinguish PNETs from other PCNs. ${ }^{2,3}$ Cystic fluid CEA levels are usually low, but amylase levels are variable. ${ }^{2}$ The cytology of PNET shows monomorphic plasmacytoid cells with granular cytoplasm and round nuclei with finely stippled and uniformly dispersed ("solid and pepper") chromatin. The diagnostic yield of cyst fluid cytological analysis is variable, as cystic PNETs may not generate as much neoplastic cells in the cyst lining as their solid counterparts. ${ }^{3}$ Currently, newer procurement devices such as the microforceps biopsy device can be introduced through a 19-G needle to sample tissue from the cyst wall, septations, and/or mural nodules, which can be processed as a cellblock. ${ }^{4 \cdot 6}$ Microforceps biopsy is associated with high technical success in providing tissue with preserved architecture for ancillary testing, carries an excellent safety profile, and can serve as a useful adjunctive tool to complement existing diagnostic protocols for PCNs. ${ }^{4-6}$ In our case, microforceps biopsy drastically changed the diagnosis, which was otherwise not suggested by cytology or cyst fluid CEA level, thereby enabling appropriate management.

Though not observed in this case, intracystic bleeding and postprocedural pancreatitis have been reported. Currently, whether postprocedural pancreatitis was a consequence of EUS-FNA could not be discerned using a $19-\mathrm{G}$ needle or the results of the microforceps biopsy. Future studies should evaluate the minimal number of passes needed with the microforceps biopsy to optimize tissue acquisition yield without 

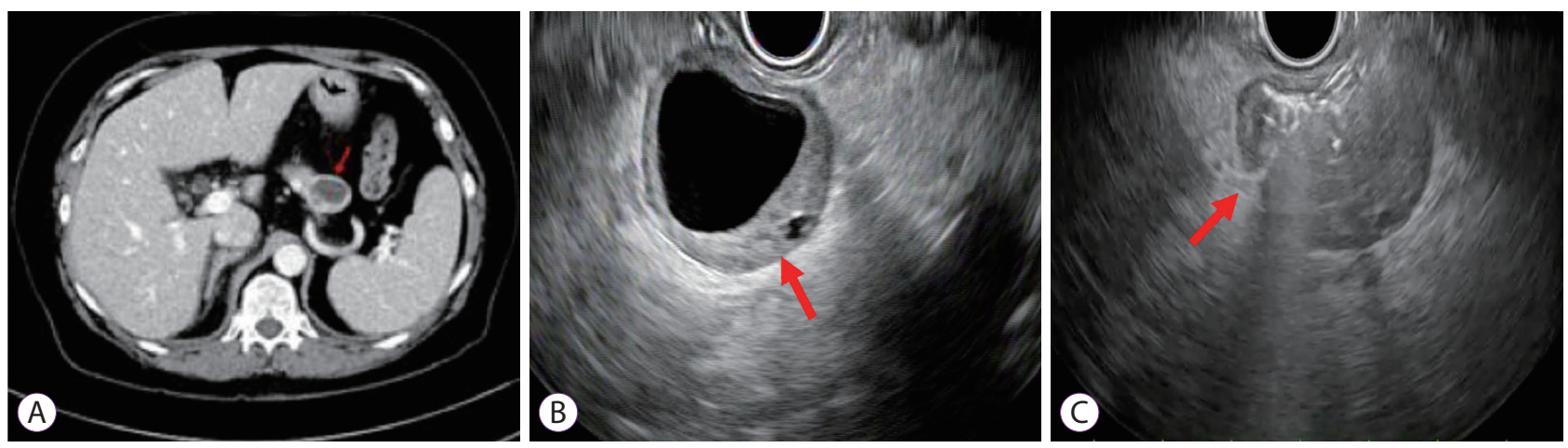

Fig. 1. (A) Contrast-enhanced computed tomography scan showing a cystic mass in the pancreatic tail. (B) Endoscopic ultrasonography (EUS) scan showing an anechoic lesion with asymmetric wall thickening. (C) EUS scan showing microforceps sampling through a 19-G needle.
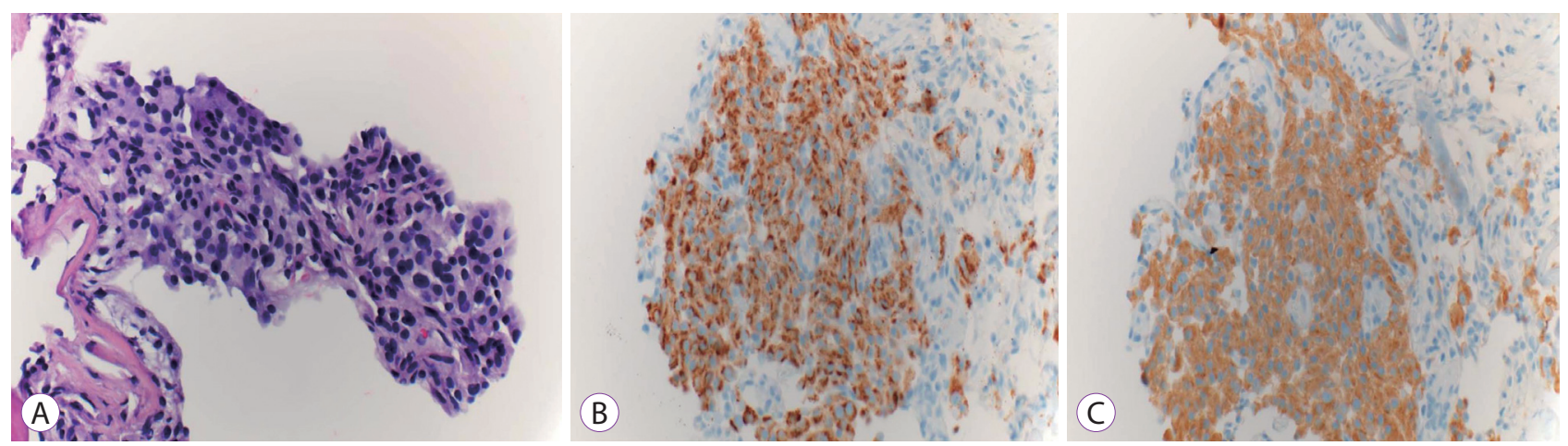

Fig. 2. Histopathology slides with $\times 40$ magnification. (A) Hematoxylin-and-eosin staining. (B) Chromogranin positivity. (C) Synaptophysin positivity.

incurring additional risks.

Sample obtained by routine FNA from a cystic PNET is usually limited by suboptimal cellularity. As microforceps biopsy provides an adequate sample for histological analysis in most cases, it is particularly useful in scenarios where ancillary studies is indicated to diagnose a specific type of PCN. Microforceps biopsy may represent a potential tool in our diagnostic armamentarium for PCNs when the diagnosis remains uncertain on the basis of only cross-sectional imaging and clinical history.

\section{Conflicts of Interest}

The authors have no financial conflicts of interest.

\section{REFERENCES}

1. Brugge WR, Lauwers GY, Sahani D, Fernandez-del Castillo C, Warshaw AL. Cystic neoplasms of the pancreas. N Engl J Med 2004;351:12181226.

2. Kongkam P, Al-Haddad M, Attasaranya S, et al. EUS and clinical characteristics of cystic pancreatic neuroendocrine tumors. Endoscopy 2008;40:602-605.

3. Yoon WJ, Daglilar ES, Pitman MB, Brugge WR. Cystic pancreatic neuroendocrine tumors: endoscopic ultrasound and fine-needle aspiration characteristics. Endoscopy 2013;45:189-194.

4. Basar O, Yuksel O, Yang DJ, et al. Feasibility and safety of microforceps biopsy in the diagnosis of pancreatic cysts. Gastrointest Endosc 2018;88:79-86

5. Mittal C, Obuch JC, Hammad H, et al. Technical feasibility, diagnostic yield, and safety of microforceps biopsies during EUS evaluation of pancreatic cystic lesions (with video). Gastrointest Endosc 2018;87:12631269.

6. Kwon CI. Will new instruments for endoscopic ultrasound-guided tissue acquisition make us happy? Clin Endosc 2018;51:510-512. 